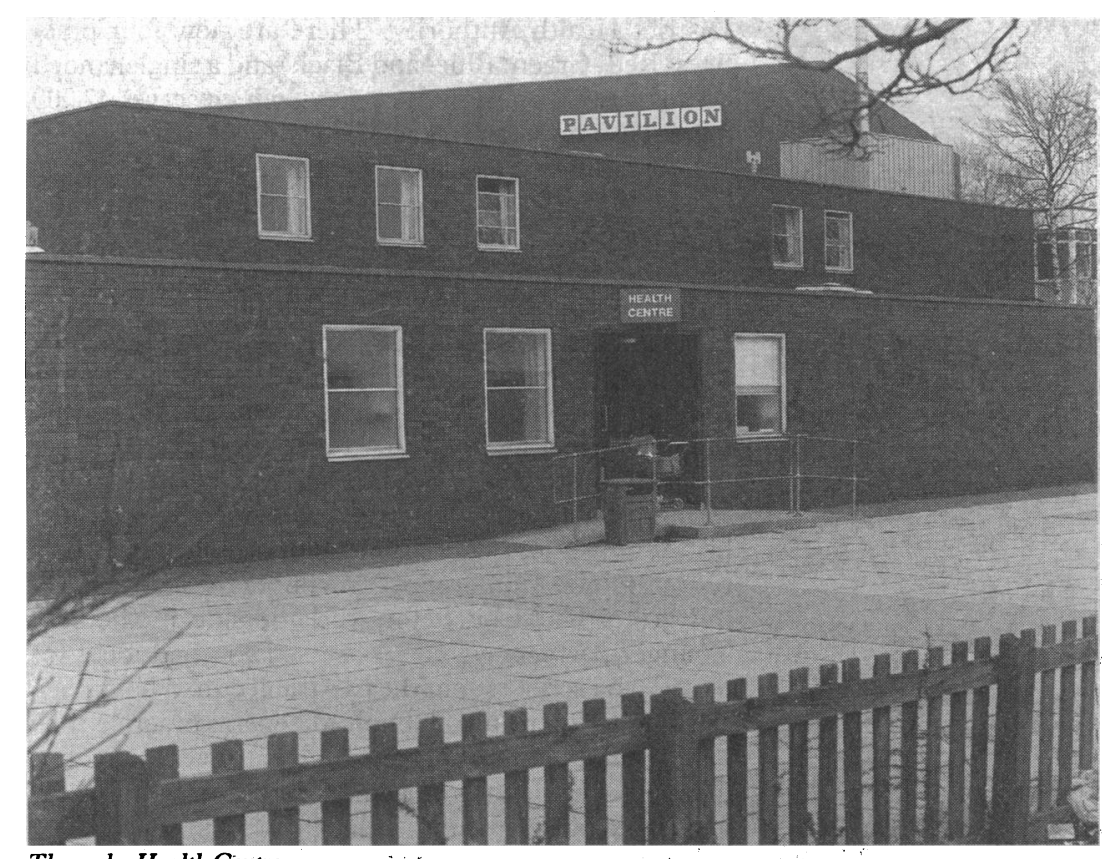

Thornaby Health Centre, Teesside, Cleveland

Department of General Practice, United Medical and Dental Schools of

Guy's and St Thomas's

Hospitals, London

SE1 9RT

David Armstrong, FFPHM, reader in sociology as applied to medicine

Beckenham, Kent

John Fry, FRCGP, general

practitioner

Bromley Local Medical Committee, Orpington Hospital, Kent

Pauline Armstrong, BA, research officer

Correspondence to: Dr Armstrong, Department of General Practice, UMDS (Guy's Campus), London SE1 9RT. tice is based in the health centre with a small branch surgery in Ingleby Barwick, a green field development of exclusively private housing. There is a combined list of 14053 patients and six partners, who have been together since 1988. The five whom I met were all in their 30s. In their view the new contract had diverted the practice from maximising the advantages of the old contract. There was considerable dissatisfaction among them and their support staff about the need for routine examination of new patients and routine health checks. "Patients don't like it either and find that registering with a doctor is about filling in lots of forms."

Despite these expressions of disquiet the practice income had increased during the past year, largely due to the previous existence of a range of clinics which now qualified for payment. The stimulus of targets had led to an increase in uptake for immunisation and cervical cytology, with the higher targets now being reached. A well organised computer system was in operation, and plans were in hand for developing more health promotion clinics. The secretaries and recep-

\author{
David Armstrong, John Fry, Pauline Armstrong
}

\section{Abstract}

Objective-To assess the effect of pressure from patients on patterns of general practitioners' outpatient referrals.

Design-Survey of general practitioners' referrals to hospital outpatient departments during one week. Setting-One health district.

Subjects-All (160) general practitioners in the health district.

Main outcome measures-Specialty of the referral, the reason for it, and its status (NHS or private) and the general practitioner's assessment of the degree of pressure exerted by the patient for the referral (much, little, or none).

Results-122 (76\%) general practitioners completed the survey. Younger general practitioners (aged $\leqslant 45$ ) and those qualifying in the United Kingdom and Republic of Ireland reported greater pressure from patients to refer $(\mathbf{p}<0.03, p<0.001$ tionists were finding increased job satisfaction: "Before it was just writing scripts and typing, now I am responsible for keeping the cervical cytology records up to date."

The scale of services now being offered had required a reappraisal of the organisation of the practice. A new practice manager was to be appointed, and discussion about this post had forced the partners to consider how best to proceed. There was a recognition of the need for building a team and dealing with unresolved issues about professional boundaries. Practice nurses were enjoying new responsibilities yet recognised the "lack of time to meet on a regular basis with doctors, who are stressed." The growth in services had highlighted the inadequacies of the health centre, and the partners were "concerned about attracting development funds for new premises."

This group practice is in transition but taking steps to tease out how best to achieve the competing demands of patient care and practice organisation. Current ideas about medical audit were submerged by an administrative workload which was only beginning to ease. The next steps were clearly about determining priorities, as opposed to merely adding more services to a practice which was already fully stretched.

\section{Reaction to contract and impact on practice}

- Still recovering from new regulations which interrupted former developments in the practice

- In transition and having difficulty working out priorities

- Moving towards more professional management

- With limited space in the health centre, uncertainty about funding applications for practice development.

\section{Next steps}

The first year of the new contract had been a time of considerable change, and the larger practices had faced major upheavals in both organisation and staffing. A subsequent article will focus on the main themes which emerged and the issues facing the practices as they take the next steps in attempting to decide future priorities.

1 Secretaries of State for Health, Wales, Northern Ireland, and Scotland. Working for patients. London: HMSO, 1990. (Cm 555.)

2 Bain J. Budget holding: a step into the unknown. BMF 1991;302:771-3.

\title{
Doctors' perceptions of pressure from patients for referral
}

respectively). Pressure was also greater for patients referred privately $(p<0.001)$, for those referred for reassurance $(p<0.05)$, and for those referred to clinics in psychiatry, rheumatology, dermatology, and orthopaedics. General practitioners with a higher referral rate (with total consultations in the week as the denominator) were more likely to report pressure $(\mathbf{p}<0.01)$.

Conclusions-The pressure from patients to refer reported by general practitioners is related both to general practitioners' characteristics and to the nature of the referral. Pressure to refer seems to explain some of the variation in referral rates among general practitioners.

\section{Introduction}

The reasons for the considerable variation in individual general practitioners' referral rates to hospital 
outpatient departments are poorly understood. ${ }^{12} \mathrm{Al}-$ though much of the variation may be due to factors relating to general practitioners, various studies have failed to show a consistent relation with a general practitioner's sociodemographic characteristics; this has led some investigators to describe the unexplained variation as most likely owing to different "referral thresholds." " A second strategy has been to examine patients' characteristics, on the grounds that the variation might be accounted for by different case mix. However, even after controlling for the patient's age, sex, social class, and diagnostic group,$^{134}$ much variation in referral patterns still remains unexplained.

A third possibility is of an interaction between general practitioner and patient in the consultation: there is already some evidence that patients and general practitioners perceive the same referral in different

TABLE I-Age of general practitioners and perceived pressure to refer. Figures are numbers (percentages) unless indicated otherwise

\begin{tabular}{|c|c|c|c|c|c|}
\hline \multirow{2}{*}{$\begin{array}{l}\text { Age } \\
\text { (years) }\end{array}$} & \multirow{2}{*}{$\begin{array}{l}\text { No of } \\
\text { referrals }\end{array}$} & \multicolumn{3}{|c|}{ Amount of pressure } & \multirow{2}{*}{$\begin{array}{l}\text { Mean } \\
\text { pressure } \\
\text { index }\end{array}$} \\
\hline & & Much & Little & None & \\
\hline$\leqslant 45$ & 481 & $67(14)$ & $138(29)$ & $276(57)$ & 0.56 \\
\hline$\geqslant 46$ & 381 & $44(12)$ & $85(22)$ & $252(66)$ & 0.45 \\
\hline
\end{tabular}

$\chi^{i}=6 \cdot 95, \mathrm{df}=2 ; \mathrm{p}<0 \cdot 03$.

TABLE II - Place of qualification of general practitioners and perceived pressure to refer. Figures are numbers (percentages) unless indicated otherwise

\begin{tabular}{|c|c|c|c|c|c|}
\hline & \multirow[b]{2}{*}{ No of referrals } & \multicolumn{3}{|c|}{ Amount of pressure } & \multirow{2}{*}{$\begin{array}{c}\text { Mean } \\
\text { pressure } \\
\text { index }\end{array}$} \\
\hline & & Much & Little & None & \\
\hline $\begin{array}{l}\text { United Kingdom and Republic of Ireland } \\
\text { Indian subcontinent }\end{array}$ & $\begin{array}{r}800 \\
62\end{array}$ & $\begin{array}{c}107(13) \\
4(6)\end{array}$ & $\begin{array}{l}218(27) \\
5(8)\end{array}$ & $\begin{array}{r}475(59) \\
53(85)\end{array}$ & $\begin{array}{l}0 \cdot 54 \\
0 \cdot 21\end{array}$ \\
\hline
\end{tabular}

$\chi^{2}=16 \cdot 73, \mathrm{df}=2 ; \mathrm{p}<0.001$.

TABLE III-General practitioners' perceived pressure to refer from private patients. Figures are numbers (percentages) unless indicated otherwise

\begin{tabular}{lccccc}
\hline & & \multicolumn{3}{c}{ Amount of pressure } & Mean \\
\cline { 3 - 6 } Patients & $\begin{array}{c}\text { No of } \\
\text { referrals }\end{array}$ & Much & Little & None & $\begin{array}{c}\text { pressure } \\
\text { index }\end{array}$ \\
\hline NHS & 714 & $79(11)$ & $183(26)$ & $452(63)$ & 0.48 \\
Private & 129 & $29(22)$ & $36(28)$ & $64(50)$ & 0.73 \\
\hline
\end{tabular}

${ }^{\star}$ Missing observations for 19 cases.

$\chi^{2}=14 \cdot 68, \mathrm{df}=2 ; \mathrm{p}<0 \cdot 001$

TABLE IV-Reason for referral and pressure to refer. Figures are numbers (percentages) unless indicated otherwise

\begin{tabular}{|c|c|c|c|c|c|}
\hline \multirow[b]{2}{*}{ Reason for referral } & \multirow[b]{2}{*}{ No of referrals ${ }^{\star}$} & \multicolumn{3}{|c|}{ Amount of pressure } & \multirow{2}{*}{$\begin{array}{c}\text { Mean } \\
\text { pressure } \\
\text { index }\end{array}$} \\
\hline & & Much & Little & None & \\
\hline Opinion & 261 & $38(15)$ & $80(31)$ & $143(55)$ & $0 \cdot 60$ \\
\hline Investigation & 141 & $10(7)$ & $38(27)$ & $93(66)$ & 0.41 \\
\hline Treatment & 422 & $57(14)$ & $96(23)$ & $269(64)$ & 0.50 \\
\hline Reassurance & 23 & $6(26)$ & $7(30)$ & $10(43)$ & 0.83 \\
\hline
\end{tabular}

Missing observations for 15 cases.

$\chi^{2}=15 \cdot 32, \mathrm{df}=6 ; \mathrm{p}<0.05$

TABLE V-Specialty of referral and perceived pressure to refer

\begin{tabular}{lcc}
\hline & \multicolumn{2}{c}{ Mean } \\
pressure & No of \\
index & referrals \\
Specialty & 0.77 & 30 \\
\hline Psychiatry & 0.69 & 48 \\
Rheumatology & 0.69 & 65 \\
Dermatology & 0.68 & 69 \\
Orthopaedics & 0.64 & 317 \\
Surgery & 0.51 & 114 \\
Gynaecology & 0.51 & 114 \\
General & & \\
$\quad$ medicine & 0.50 & 113 \\
Paediatrics & 0.48 & 25 \\
Geriatrics & 0.17 & 18 \\
Obstetrics & 0.12 & 57 \\
\hline Mean/total & 0.52 & 856 \\
\hline
\end{tabular}

ways. ${ }^{5}$ One way this interaction might occur is through the amount of pressure to refer applied by different patients on their general practitioner and, conversely, different general practitioners' recognition and reaction to such pressure.

In a survey of outpatient referrals in a health district we asked all general practitioners to record the amount of pressure they felt that they had experienced from each referred patient, to see if this related to any attributes of the general practitioner, their patient, or the reason for referral.

\section{Methods}

We invited all general practitioners in the Bromley health district to take part in a survey of their hospital outpatient referrals over one week. As well as identifying each referral as it occurred, they were also asked to record the reason for the referral; whether it was a private or NHS referral; the specialty of the referral; and, in addition, the degree of pressure experienced from the patient for the referral. Pressure was measured on a subjective three point scale: general practitioners were invited to describe whether much, little, or no pressure was exerted by the patient. Basic sociodemographic data on all general practitioners in the district were obtained from the family practitioner committee using a system of code numbers to protect anonymity.

Data were collated and analysed with the statistical package for the social sciences. Characteristics of the general practitioners, patients, and referrals were cross tabulated with pressure to refer: significance was determined by $\chi^{2}$ testing.

\section{Results}

Out of 160 general practitioners in the district, 122 responded and returned audit sheets, giving a response rate of $76 \%$. The general practitioners who responded did not differ significantly in terms of age, sex, or size of partnership from those who did not. Overall, the general practitioners who responded had 16800 consultations in the week of the survey and recorded 954 outpatient referrals. In 92 cases they failed to report the degree of pressure experienced: the following results are therefore based on 862 referrals.

In $526(61 \%)$ of referrals general practitioners reported that there was no pressure from the patient to refer, in $224(26 \%)$ that there was a little pressure, and in $112(13 \%)$ that there was much pressure.

There was no relation between the sex of the general practitioners or that of the patients and reported pressure to refer. However, general practitioners aged under 45 were more significantly likely than older general practitioners to experience such pressure, as shown by calculating an index of pressure for each age group by scoring the pressure scale numerically (much pressure $=2$, little pressure $=1$, and no pressure $=0$ ) and then obtaining a mean index for patients seen by each general practitioner age group (table I). Pressure to refer did not vary by age of patient.

The place of qualification of the general practitioners was established from the medical school at which they trained. Table II shows that general practitioners qualifying in the United Kingdom and Republic of Ireland were significantly more likely to report experiencing pressure to refer from their patients.

Fifteen per cent (129/843) of referrals in the district were private referrals (mainly covered by prepaid insurance), and, as table III shows, patients referred privately were significantly more likely to exert pressure for the referral than NHS patients.

Table IV shows the reason for referral according to the degree of pressure exerted by the patients. Most pressure for referral came from the few patients who were referred exclusively for reassurance.

The pressure placed on the doctor by the patient varied by the referral specialty. Most pressure was experienced with patients referred to psychiatry and then those referred to rheumatology, dermatology, and orthopaedics (table V).

Overall referral rates were calculated for each general practitioner by dividing the actual number of referrals during the week by the total consultation load. On this basis the general practitioners in the sample were divided into four groups of equal size representing high, fairly high, fairly low, and low referrers. Those general practitioners with a high referral rate reported significantly greater perceived pressure from the patient for referral (table VI). 
TABLE VI-Rate of referrals and perceived pressure to refer. Figures are numbers (percentages) unless indicated otherwise

\begin{tabular}{|c|c|c|c|c|c|}
\hline \multirow[b]{2}{*}{ Referral rates/ 100 consultations } & \multirow[b]{2}{*}{ No of referrals } & \multicolumn{3}{|c|}{ Amount of pressure } & \multirow{2}{*}{$\begin{array}{l}\text { Mean } \\
\text { pressure } \\
\text { index }\end{array}$} \\
\hline & & Much & Little & None & \\
\hline$\leqslant 4 \cdot 19$ & 101 & 14 & 14 & 73 & $0 \cdot 42$ \\
\hline $4 \cdot 20-5 \cdot 73$ & 202 & $19(9)$ & $49(24)$ & $134(66)$ & 0.43 \\
\hline $5 \cdot 74-7 \cdot 94$ & 242 & $26(11)$ & $75(31)$ & $141(58$ & 0.52 \\
\hline$\geqslant 7.95$ & 317 & $52(16)$ & $85(27)$ & $180(57)$ & $0 \cdot 60$ \\
\hline
\end{tabular}

\section{Discussion}

It is important to emphasise that the variable of patient pressure as measured in this study relates to the general practitioners' perceptions. It is possible that in some cases the patient exerted pressure but the general practitioner failed to appreciate it or, conversely, that the patient was not exerting pressure but was perceived as doing so. Thus the pressure studied in this investigation must reflect the interaction between patients' behaviour and doctors' perception. For example, the higher rate of pressure reported by younger doctors and by those graduating in the United Kingdom and Republic of Ireland compared with those graduating overseas may not indicate that patients are more likely to select these doctors, either consciously or subconsciously, as targets for persuasion but rather that these doctors are more likely to be aware of this pressure, as well as being more likely to report it. Thus general practitioners trained abroad or more than 20 years ago in the United Kingdom and Republic of Ireland may be less sensitive to the cues for a referral that patients might offer.

The increased pressure for referral by patients with private insurance, often simply for reassurance, may be recognised by many general practitioners. However, this finding has particular importance as the health service moves into a new organisational context in which privatisation and consumer rights are being emphasised. If patients are persuaded that they have rights as consumers to make demands on general practitioners for the type and quality of care they receive increasing pressures on general practitioners to make referrals might be expected. This might not only increase actual referrals but also create tensions in those consultations, especially in fundholding practices, where some attempt is made to limit use of resources.

As might be expected, the amount of pressure varied by the reason for the referral, with referrals for reassurance being reported as generating most pressure. Consultations in which patients were referred for investigation were reported as generating less pressure, possibly because many of these were instances in which the illness was at such an early stage that the patient either was not seriously concerned or was unable to judge the most appropriate course of action.

Reported pressure varied by specialty of referral: the largest specialties of medicine, surgery, and gynaecology were associated with "average" pressure whereas psychiatry, rheumatology, dermatology, and orthopaedics were associated with more pressure and geriatrics and obstetrics with considerably less. In psychiatry the pressure may be from relatives who find the patient's behaviour difficult; pressure in the other three "high pressure" specialties may reflect various factors, such as more difficult access to services (particularly lengthy waiting lists) and chronic conditions for which patients have already been treated, perhaps without dramatic success, by their general practitioner. This would be supported by the low levels of reported pressure in obstetrics, where referral for antenatal care is routine.

Finally, does patient pressure shed any light on the variation in referral rates? As shown in table VI there was a clear relation between referral rate and reported patient pressure. This suggests that further exploration of the interaction between general practitioner and patient might help to explain the variability of general practitioner referral patterns, especially in the relation between the pressure applied by the patient and the general practitioner's awareness of and response to it.

We thank the general practitioners in the Bromley health district who took part in this study. This research is part of a project funded by the South East Thames Regional Health Authority Primary Care Development Fund.

\section{Wilkin D, Smith A. Explaining variation in general practitioner referrals to hospital. Fam Pract 1987;4:160-9. \\ 2 Wilkin D, Dornan C. General practitioner referrals to hospital: a review of research and its implications for policy and practice. Manchester: University of Man- chester, 1990. \\ 3 Cummins RO, Jarman B, White P. Do general practitioners have differen "referral thresholds"? BMF 1981;282:1037-9. \\ 4 Morrell DC, Gage HG, Robinson NA. Referrals to hospital by general practitioners. F R Coll Gen Pract 1971;21:77-85. \\ 5 Grace JG, Armstrong D. Referral to hospital: perceptions of patients, genera practitioners and consultants about necessity and suitability of referral. Fam Pract 1987;4:170-5.}

(Accepted 4 April 1991)
In retrospect many of those who lived through the London blitz came to view the experience with nostalgia. It was a time of danger, privation, and anxiety, but also of camaraderie and fellowship. There is, however, little sense of the fun and pleasures of community to be detected in the fournal's coverage of air raid shelters. Its centennial number included an article on hygiene in the shelters. This began: "Air-raid shelters were at first regarded with indifference, but as daylight raiding developed they became places of refuge for an hour. With the onset of allnight raiding, however, they have become dormitories, and the health problems they create have become urgent.' The solitude, discomfort, and cold of domestic Anderson shelters encouraged up to one third of the London population to frequent communal shelters, including underground railway stations. The resulting "nightly scenes ... with their sprawling multitudes on every kind of rough upholstery, have to be seen to be believed." Il ventilated and lacking lavatories, some underground stations were grossly overcrowded, dirty, and insanitary:
"Until the rush hour is over and the staff are free to clean up, the stench of the platforms and passages ... . is overpowering. 'Tube (or shelter) sore throat' is said to be already a common complaint." The fournal feared the onset of serious epidemics as winter advanced, and called for provision of proper sitting, sleeping, and sanitary facilities, as well as for light, warmth, ventilation, first aid, and medical provision. If doctors were organised on a rota they would be able to weed out cases of infectious disease and encourage improved personal hygiene. The alternative was "a state of affairs in respect of infectious and contagious diseases which may prove more devastating than the Blitzkrieg."

From Mirror of Medicine: A History of the BMF by $\mathrm{P} W$ Bartrip. Published jointly by the $B M F$ and Oxford University Press; BMA members' price UK $£ 29$, overseas $£ 33$, including postage. Obtainable from the Publishing Manager, $B M \mathcal{F}$, PO Box 295, London WC1H 9TE. Non-members UK $£ 35$ Obtainable from OUP Distribution Services, Saxon Way West, Corby, Northamptonshire NN18 9ES. 